\title{
MAGNETRON SPUTTERING DEPOSITION OF HIGH ENTROPY NITRIDES FROM CHROMIUM- HAFNIUM-MOLYBDENUM-TANTALUM-WOLFRAM SYSTEM
}

\author{
Tomasz STASIAK ${ }^{1}$, Pavel SOUČEK ${ }^{1}$, Vilma BURŠÍKOVÁ ${ }^{1}$, Petr VAŠINA ${ }^{1}$ \\ ${ }^{1}$ Department of Physical Electronics, Faculty of Science, Masaryk University, Brno, Czech Republic, EU, \\ tomasz.stasiak@mail.muni.cz
}

https://doi.org/10.37904/nanocon.2021.4312

\begin{abstract}
High entropy alloys (HEAs) are multicomponent materials with at least five elements close to the equiatomic ratio. The multielement composition leads to many effects that stabilize solid solution phases instead of intermetallic compounds. It results in promising mechanical properties, high thermal stability, good corrosion resistance, etc. After the discovery of HEAs in 2004 , the concept only concerned metallic materials. Later, the idea was extended to high entropy ceramics (carbides, nitrides, oxides). In this study, the high entropy nitrides (HENs) from the Cr-Hf-Mo-Ta-W system were deposited by magnetron sputtering from elemental segmented targets. Two series of samples were deposited under different nitrogen flow from $0 \mathrm{sccm}$ to $20 \mathrm{sccm}$ at ambient temperature and $700{ }^{\circ} \mathrm{C}$. The coatings deposited at low nitrogen flow consist predominantly of metallic and amorphous phases. At higher nitrogen flow (above $10 \mathrm{sccm}$ ), the coatings mainly consist of multielement facecentered cubic nitride with nanometric grain size, which lattice parameter increases with increasing nitrogen content. The chemical composition of films varies as a function of nitrogen flow and temperature. With increasing nitrogen flow and temperature, the deposition rate decreases from $67 \mathrm{~nm} \mathrm{~min}{ }^{-1}$ at ambient temperature with no nitrogen to $38 \mathrm{~nm} \mathrm{~min}^{-1}$ at $700{ }^{\circ} \mathrm{C}$ under $20 \mathrm{sccm}$ nitrogen flow. The coatings revealed high hardness up to $26.6 \mathrm{GPa}$ and Young's modulus up to $531 \mathrm{GPa}$.
\end{abstract}

Keywords: High entropy alloys, high entropy ceramics, nitrides, magnetron sputtering deposition, thin films

\section{INTRODUCTION}

High entropy alloys (HEAs) are multicomponent alloys that contain at least five elements in a near equiatomic ratio [1-3]. The concept was introduced independently by two research groups led by Cantor [1] and Yeh [2] in 2004. Since then, many articles describing different systems from almost infinite possible compositions of HEAs have been published. HEAs reveal many promising properties, such as high mechanical resistance at high and low temperatures, creep, oxidation, corrosion, and hydrogen embrittlement resistance, that can compete with many traditional alloys [4]. The reason for these properties could be explained by four core effects. The effects, such as high entropy, lattice distortion, sluggish diffusion, and cocktail effect, present due to the multielement composition of HEAs, can partially explain the exceptional properties of this group of materials [3]. Among HEAs, the alloys based on refractory elements were given significant attention in recent years. It is mainly thanks to exceptional mechanical properties in bulk materials [5] and thin films [6].

The concept of metallic HEAs was quickly expanded to high entropy ceramics (HECs), i.e., carbides, nitrides, oxides. The high entropy nitrides (HENs) deposited as thin films seem to be studied the most frequently among HECs. The first publication dealing with a reactive magnetron sputtering deposition of nitrides from the Al-CrTa-Ti-Zr system already showed high hardness and elastic modulus, 32 and $368 \mathrm{GPa}$, respectively [7]. Later studies confirmed the very high mechanical resistance of other HENs, often reaching hardness values above $25 \mathrm{GPa}$ [8-10]. Most HENs consist of a single phase of multielement $\mathrm{NaCl}$-type face-centered cubic structure [11]. The formation of a single solid solution phase confirms the presence of a high entropy effect in this group 
of materials. Moreover, HENs reveal other promising properties such as good corrosion resistance [8,10], good oxidation resistance [12], promising tribological properties (low friction coefficient and high wear resistance) [9]. The properties mentioned above make HENs very good candidates for high resistant protective coatings in many industrial applications. In this paper, the investigation focus on the deposition of the HEAs and HENs coatings from the $\mathrm{Cr}-\mathrm{Hf}-\mathrm{Mo}-\mathrm{Ta}-\mathrm{W}$ system by reactive magnetron sputtering. The microstructure and mechanical properties were investigated as a function of nitrogen flow and deposition temperature.

\section{EXPERIMENTAL METHODS}

The coatings were deposited on silicon substrate by an HVM Flexilab magnetron sputtering device (HVM Plasma spol s.r.o., Czech Republic) from elemental segmented targets. Each circular target of a diameter of $50.8 \mathrm{~mm}$ and thickness of $3 \mathrm{~mm}$ was cut into four equal pieces. Based on the sputtering yield [13] and preliminary experimental data, the segments of the targets were divided into three cathodes to obtain a nearequiatomic composition of coatings. Cathodes contained four parts of $\mathrm{Cr}$ (Cathode 1), two pieces of Mo and two pieces of $\mathrm{Hf}$ (Cathode 2), two segments of Ta and two segments of $\mathrm{W}$ (Cathode 3). The power delivered to the cathodes was set as 80,150 , and $150 \mathrm{~W}$ for cathode 1, 2, and 3, respectively. Si (100) was used as the substrate for the films. The argon flow was fixed at $80 \mathrm{sccm}$ (standard cubic centimeter per minute), resulting in a pressure of $1.20 \mathrm{~Pa}$. Two series of depositions were performed under various nitrogen flows between 0 $20 \mathrm{sccm}$ at room temperature (RT) and high temperature $\left(\mathrm{HT}, 700^{\circ} \mathrm{C}\right)$. The base pressure before a deposition was about $2 \cdot 10^{-4} \mathrm{~Pa}$. The deposition time was 30 minutes. Rotation of the substrate holder was set to $5 \mathrm{rpm}$ to ensure homogenous distribution of elements. The structure of the deposited coatings was investigated by X-Ray Diffraction (XRD) using a Rigaku SmartLab diffractometer (Rigaku, Japan) with a copper Ka radiation source $(\lambda=1.54056 \AA)$. The microstructure, chemical composition, and deposition rate were studied using a TESCAN MIRA 3 scanning electron microscope (SEM) (TESCAN, Czech Republic) coupled with energydispersive X-ray spectroscopy (EDX) detector X-MAX50 (Oxford Instruments, UK). The hardness and effective Young's modulus were measured using a Hysitron 950 (Bruker, Germany/USA) using the XPM mode under a load of $20 \mathrm{mN}$. At least 100 indentations were acquired for each sample to obtain reliable results.

\section{RESULTS AND DISSCUSSION}

\subsection{Chemical composition}

The SEM-EDX measurements, shown in Table 1, revealed significant changes of chemical composition.

Table 1 Chemical composition (at. \%) of coatings deposited at RT and HT under different flows of nitrogen

\begin{tabular}{|c|c|c|c|c|c|c|c|c|c|c|c|c|}
\hline \multirow{2}{*}{$\begin{array}{l}\text { Nitrogen fl./ } \\
\text { depostion } \\
\text { temp. }\end{array}$} & \multicolumn{2}{|c|}{ Cr (at. \%) } & \multicolumn{2}{|c|}{ Hf (at. \%) } & \multicolumn{2}{|c|}{ Mo (at. \%) } & \multicolumn{2}{|c|}{ Ta (at. \%) } & \multicolumn{2}{|c|}{ W (at. \%) } & \multicolumn{2}{|c|}{ N (at. \%) } \\
\hline & RT & HT & RT & HT & RT & HT & RT & HT & RT & HT & RT & HT \\
\hline $0 \mathrm{sccm}$ & 22.7 & 23.1 & 16.7 & 14.9 & 22.8 & 23.3 & 19.6 & 19.4 & 18.2 & 19.3 & 0.0 & 0.0 \\
\hline $5 \mathrm{sccm}$ & 14.8 & 14.8 & 10.4 & 9.9 & 16.5 & 19.7 & 14.1 & 13.2 & 16.2 & 16.5 & 28.0 & 25.9 \\
\hline $10 \mathrm{sccm}$ & 13.4 & 13.9 & 6.0 & 6.4 & 14.7 & 17.9 & 10.4 & 11.4 & 15.0 & 16.7 & 40.5 & 33.7 \\
\hline $15 \mathrm{sccm}$ & 12.7 & 13.3 & 4.2 & 5.0 & 14.3 & 17.6 & 9.1 & 9.7 & 15.2 & 15.7 & 44.5 & 38.7 \\
\hline $20 \mathrm{sccm}$ & 12.0 & 12.8 & 3.6 & 4.5 & 14.5 & 18.3 & 8.7 & 9.5 & 15.3 & 17.3 & 45.9 & 37.6 \\
\hline
\end{tabular}

As expected, with increasing $\mathrm{N}_{2}$ flow, the nitrogen content in the coatings increases. It is the highest for the sample deposited at RT under $20 \mathrm{sccm} \mathrm{N} \mathrm{N}_{2}$ flow. It should be noted that the rise of nitrogen content with increasing its flow is not linear. The increase is fast for a small $\mathrm{N}_{2}$ flow; however, the difference between 15 and $20 \mathrm{sccm}$ is minimal due to saturation. The content of the metallic elements decreases with increasing $\mathrm{N}_{2}$ flow, especially the drop of $\mathrm{Hf}$ and $\mathrm{Ta}$ is higher than that of other elements. It can be explained by more 
significant poisoning of these metals, i.e., the formation of the $\mathrm{N}$-containing layer on the target surface, which decreases sputtering yield. The temperature during deposition also affects the chemical composition. The effect of temperature on the metallic elements is relatively small; however, the impact on the nitrogen content is significant.

\subsection{Crystallographic structure}

The XRD patterns, shown in Figure 1, showed important differences between samples deposited under different nitrogen flows. The coatings prepared only under Ar flow at RT and HT reveal a crystallographic structure composed of three body-centered cubic $(\mathrm{bcc})$ phases with the lattice parameters close to pure Ta, Mo, and $\mathrm{W}$. The temperature during deposition has an impact on the structure of the metallic coatings. The texture shift is observed from a (110) and (211) at RT to a (200) at HT. The $\mathrm{N}_{2}$ flow of $5 \mathrm{sccm}$ leads to the formation of an amorphous structure at RT, while the samples prepared at HT present mainly bcc phase $(\mathrm{a}=$ $3.092 \AA$ ) and probably some fraction of the amorphous phase too. The amorphization of the structure under low nitrogen flow could be related to the excess interstitial nitrogen in the bcc phases and the simultaneous lack of sufficient nitrogen content to form multielement nitride. The higher $\mathrm{N}_{2}$ flow results in multielement facecentered cubic (fcc) NaCl-type nitride formation. The formation of nitride solid-solution could be attributed to the high entropy effect, which by increasing solubility, limits the formation of intermetallic phases between nitrogen and metallic elements [9]. Similar nitride phases were found in other HEN coatings [8,9,14]. Besides the main phase, some small peaks of fcc phases with slightly different lattice parameters are also present. The lattice parameter and crystallite size of multielement fcc nitride change as a function of $\mathrm{N}_{2}$ flow and temperature, which is shown in Table 2. The deposition at the HT leads to a smaller lattice parameter and bigger crystallite size for a given $\mathrm{N}_{2}$ flow than the deposition at RT. The HT enhances diffusivity and mobility, and therefore it results in bigger crystallite size. The increase of nitrogen flow results in a bigger lattice parameter and a smaller crystallite size.
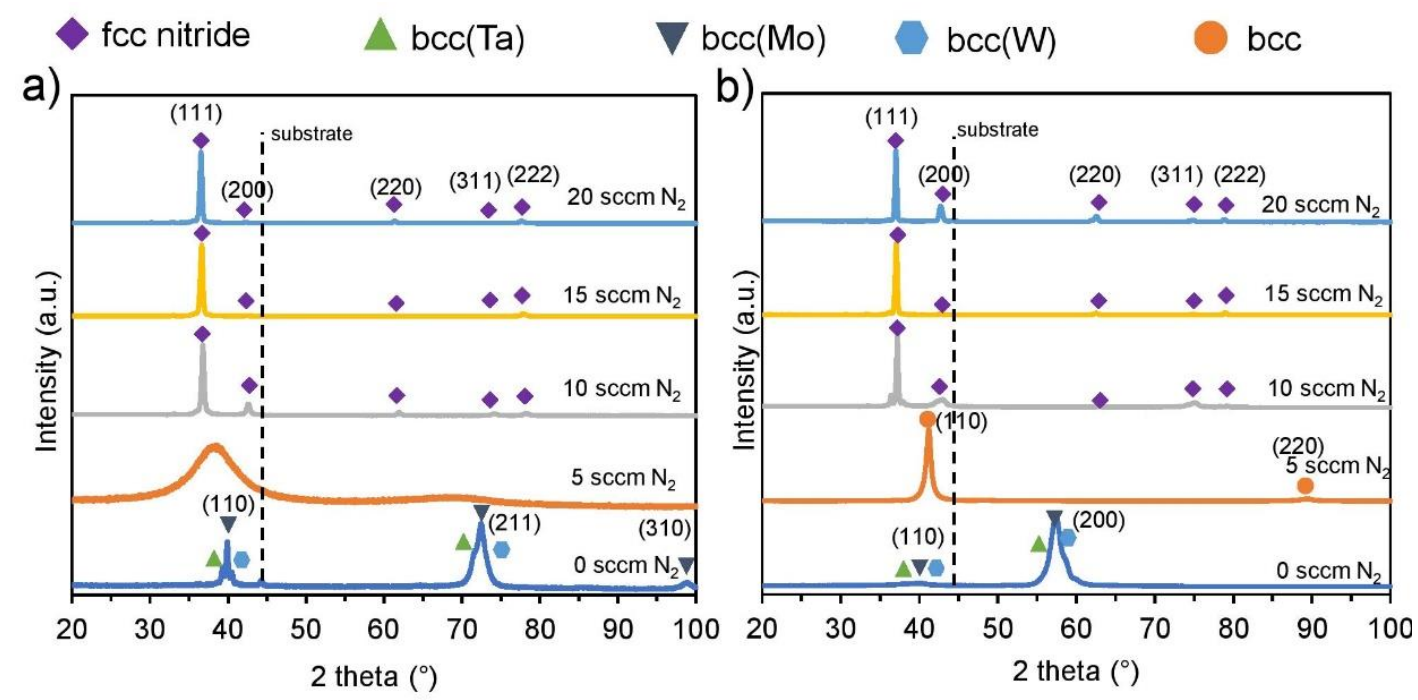

Figure 1 X-ray diffraction patterns of coatings deposited at RT (a) and HT (b) under flow of nitrogen

Table 2 Lattice parameter and crystallite size of fcc multielement nitrides

\begin{tabular}{|c|c|c|c|c|}
\hline \multirow{2}{*}{$\begin{array}{c}\text { Nitrogen Flow } \\
\text { (sccm) }\end{array}$} & \multicolumn{2}{|c|}{ Lattice parameter $(\mathbf{A})$} & \multicolumn{2}{c|}{ Crystallite size (nm) } \\
\cline { 2 - 5 } & $\mathbf{R T}$ & HT & RT & HT \\
\hline 10 & 4.236 & 4.193 & 17.2 & 33.0 \\
\hline 15 & 4.252 & 4.202 & 16.3 & 32.4 \\
\hline 20 & 4.268 & 4.220 & 15.4 & 23.7 \\
\hline
\end{tabular}




\subsection{Microstructure and deposition rate}

The SEM observations of the cross-section of coatings, shown in Figure 2, reveal significant differences in microstructure between conditions. The sample prepared at RT without nitrogen flow presents a columnar microstructure, while the coating deposited at HT shows a more dense microstructure without easily distinguishable columns. Both samples (RT and $\mathrm{HT}$ ) prepared under $5 \mathrm{sccm}$ nitrogen flow present a very dense cross-section. The coatings deposited under higher nitrogen flow $(10-20 \mathrm{sccm})$ show a typical columnar structure. The columns are slightly wider for the HT series than for the RT series, and their size decreases with increasing nitrogen flow. It seems that the coatings deposited at high nitrogen flow show more porosity.
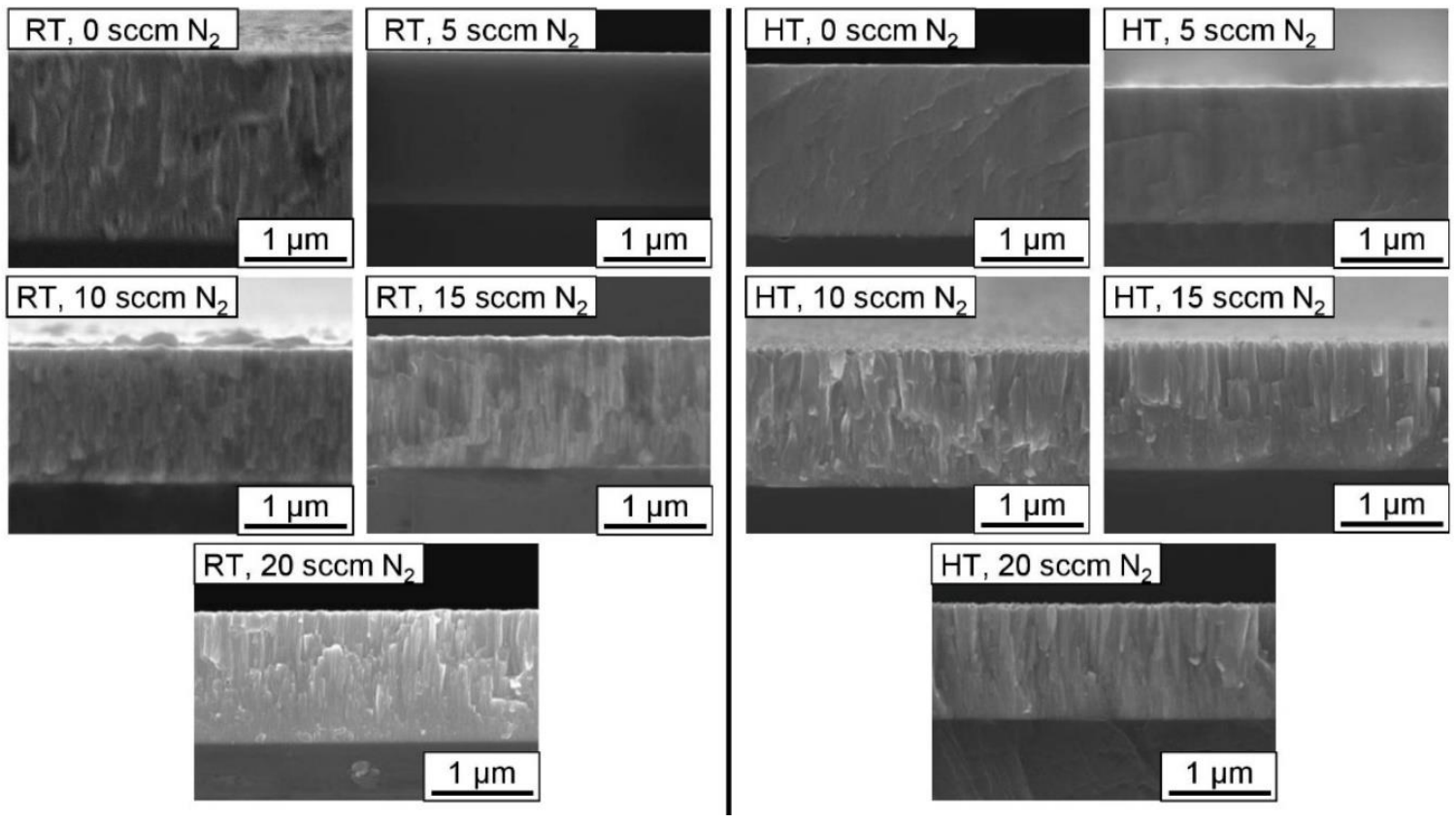

Figure 2 SEM images of the cross section of coatings deposited at RT and HT under flow of nitrogen

The deposition rate, shown in Figure 3, is relatively high for all prepared coatings. Nevertheless, it is decreasing with increasing nitrogen flow. It can be a result of more severe partial poisoning of the targets [14]. The temperature seems to play a less significant role, mainly by slightly reducing the deposition rate of samples prepared without nitrogen. However, the HT could lead to densification of coatings, and therefore slightly decreasing the thickness and consequently the deposition rate.

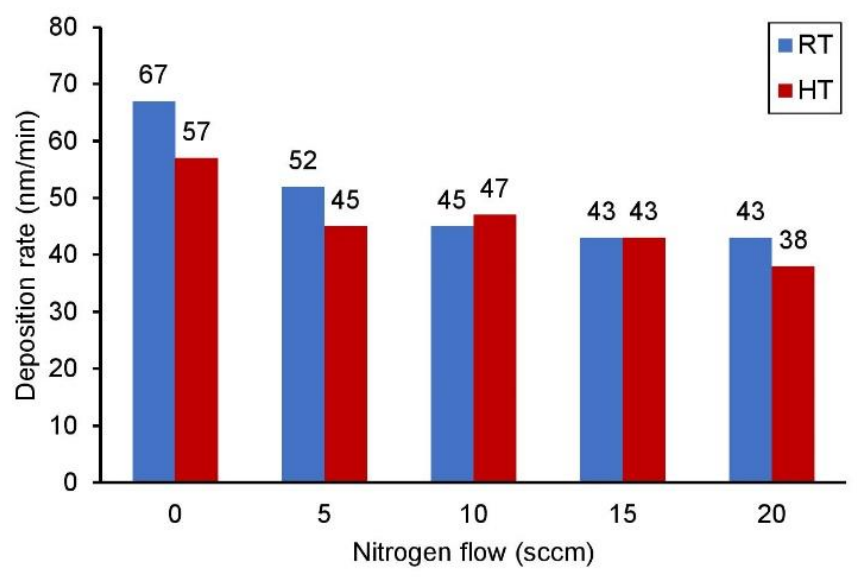

Figure 3 Deposition rate of coatings prepared under different flows of nitrogen at RT and HT 


\subsection{Mechanical properties}

The mechanical properties evaluated based on the microindentation test, shown in Figure 4, are very promising. The pure metallic samples reveal a good hardness level, with the sample deposited at HT showing higher hardness due to lower porosity. The highest hardness (26.6 GPa) among tested samples was measured for the coating deposited at HT under $5 \mathrm{sccm} \mathrm{N} \mathrm{N}_{2}$ flow. This sample consists mainly of the bcc phase and some fraction of the amorphous phase. The cross-section images revealed a very high density. The completely amorphous sample deposited at $5 \mathrm{sccm} \mathrm{N}_{2}$ flow present also high hardness. The coatings with the fcc multielement nitride deposited at higher nitrogen flow show lower hardness. The HT deposition series between 10 and $20 \mathrm{sccm}$ reveal hardness of about $14.0 \mathrm{GPa}$. It is a quite low value compared to metallic and amorphous coatings due to significantly higher porosity. The RT deposition series show decreasing hardness with increasing $\mathrm{N}_{2}$ flow. It could be related to a slight increase of porosity. Nevertheless, the deposition at RT leads to a slightly higher hardness than at HT. It could be associated with a smaller crystallite size.
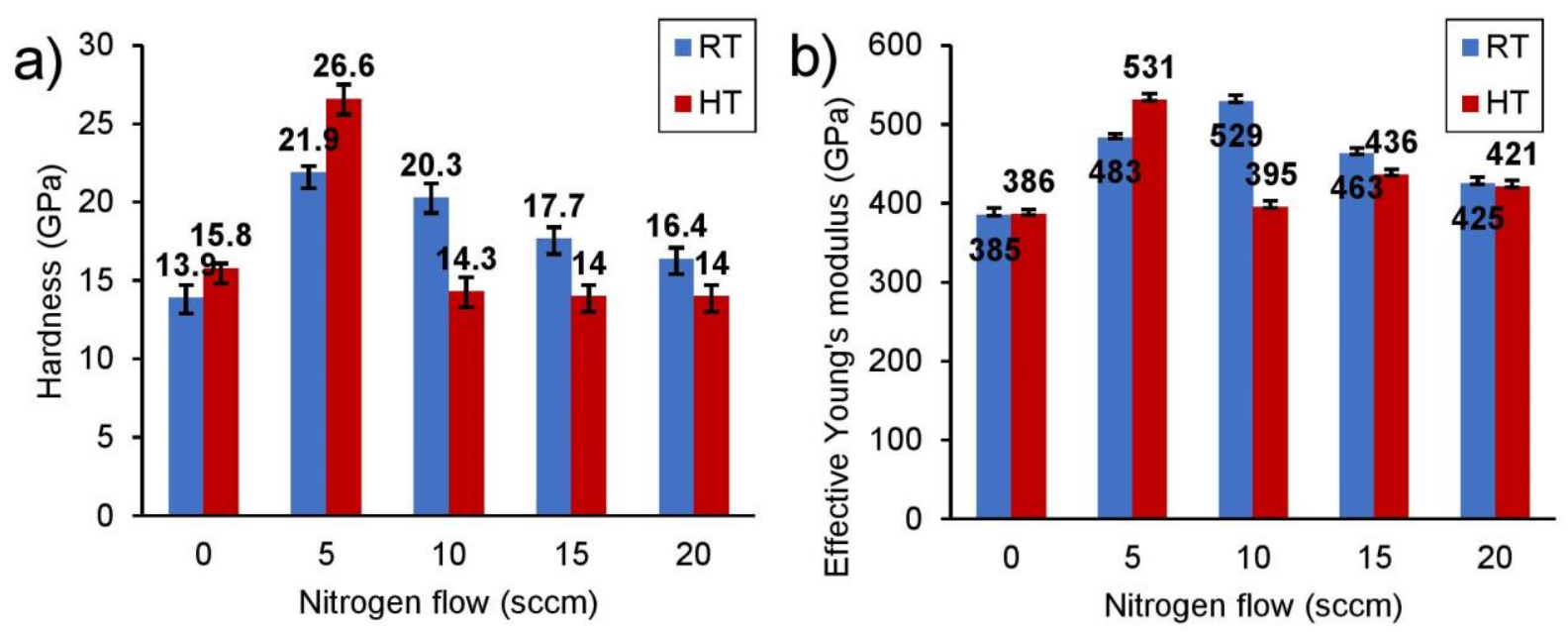

Figure 4 Hardness (a) and effective Young's modulus (b) of coatings deposited at RT and HT

The effective Young's modulus (E) of metallic coatings is about $385 \mathrm{GPa}$ for samples deposited at RT and HT. Similar to the hardness, the effective Young's modulus is the highest for the samples deposited at $5 \mathrm{sccm}$, especially for that prepared at $\mathrm{HT}(531 \mathrm{GPa})$. For the coatings which consist of multielement nitride, the $\mathrm{E}$ decreases with increasing nitrogen flow for the RT series. For the HT series, the effective Young's modulus is somewhat similar between samples prepared between 10 and $20 \mathrm{sccm}$ nitrogen flow. The decrease of the effective Young's modulus could be associated with the formation of defects such as pores.

\section{CONCLUSION}

Coatings of HEAs and HENs from the Cr-Hf-Mo-Ta-W family were successfully deposited by reactive magnetron sputtering from segmented elemental metallic targets. The paper describes the effect of the deposition conditions (temperature, nitrogen flow) on the microstructure and mechanical properties. The results show a decrease of metallic element content and an increase of nitrogen with the increasing nitrogen flow. Coatings deposited at low $\mathrm{N}_{2}$ flows consist either of metallic or amorphous phases. The higher nitrogen flow leads to the formation of a major multielement fcc nitride phase with the lattice parameter slightly increasing with increasing nitrogen content and smaller for high-temperature series. The multielement nitride consists of nanometric grains between 15.4 and $33.0 \mathrm{~nm}$, which decrease with increasing nitrogen flow. The deposition rate drops with increasing nitrogen flow, and it is slightly lower for the HT series. Cross-section observations reveal columnar structure in samples consisting of the fcc nitride and dense microstructure deposited at low nitrogen flow. The deposited coating present very high hardness and effective Young's 
modulus. Especially high hardness up to 26.6 GPa was found in dense coating deposited at low nitrogen flow. The promising results presented in this paper, which are the first experimental study of the HENs from the CrHf-Mo-Ta-W system, encourage further, more detailed investigations.

\section{ACKNOWLEDGEMENTS}

\section{This research was supported by project LM2018097 funded by the Ministry of Education, Youth and Sports of the Czech Republic.}

\section{REFERENCES}

[1] CANTOR, B., CHANG, I.T.H., KNIGHT, P., VINVENT, A.J.B. Microstructural development in equiatomic multicomponent alloys. Mater. Sci. Eng. A. 2004., vol. 375-377, pp. 213-218.

[2] YEH, J.-W., CHEN, S.-K., LIN, S.-J., GAN, J.-Y., CHIN, T.-S., SHUN, T.-T., TSAU, C.-H., CHANG, S.-Y. Nanostructured High-Entropy Alloys with Multiple Principal Elements: Novel Alloy Design Concepts and Outcomes. Adv. Eng. Mater. 2004, vol. 6, pp. 299-303.

[3] YEH, J.-W. Recent Progress in High Entropy Alloys. Ann. Chim. - Sci. Des Matériaux. 2006, vol. 31, pp. 633648.

[4] GEORGE, E.P., RAABE, D., RITCHIE, R.O. High-entropy alloys. Nat. Rev. Mater. 2019, vol. 4, pp. 515-534.

[5] SENKOV, O.N., WILKS, G.B., SCOTT, J.M., MIRACLE, D.M. Mechanical properties of Nb25Mo25Ta25W25 and V20Nb20Mo20Ta20W20 refractory high entropy alloys. Intermetallics. 2011, vol. 19, pp. 698-706.

[6] KIM, H., NAM, S., ROH, A., SON, M., HAM, M.H., KIM, J.H., CHOI, H. Mechanical and electrical properties of NbMoTaW refractory high-entropy alloy thin films. Int. J. Refract. Met. Hard Mater. 2019, vol. 80, pp. 286-291.

[7] LAI, C.H., LIN, S.J., YEH, J.W., CHANG, S.Y. Preparation and characterization of AICrTaTiZr multi-element nitride coatings. Surf. Coatings Technol. 2006, vol. 201, pp. 3275-3280.

[8] VON FIEANDT, K., PASCHALIDOU, E.M., SRINATH, A., SOUCEK, P., RIEKEHR, L., NYHOLM, L., LEWIN, E. Multi-component (Al, $\mathrm{Cr}, \mathrm{Nb}, \mathrm{Y}, \mathrm{Zr}) \mathrm{N}$ thin films by reactive magnetron sputter deposition for increased hardness and corrosion resistance. Thin Solid Films. 2020, vol. 693, 137685.

[9] CUI, P., LI, W., LIU, P., ZHANG K., MA, F., CHEN, X., FENG, R., LIAW, P.K. Effects of nitrogen content on microstructures and mechanical properties of (AICrTiZrHf) N high-entropy alloy nitride films. J. Alloys Compd. 2020, vol. 834, 155063.

[10] SHU, R. PASCHALIDOU, E.M., RAO, S.G., LU, J., GRECZYNSKI, G., LEWIN, E., NYHOLM, L., LE FEBVRIER, A., EKLUND, P. Microstructure and mechanical, electrical, and electrochemical properties of sputter-deposited multicomponent (TiNbZrTa)Nx coatings. Surf. Coatings Technol. 2020, vol. 389, 125651.

[11] OSES, C., TOHER, C., CURTAROLO, S., High-entropy ceramics. Nat. Rev. Mater. 2020, vol. 5, pp. 295-309.

[12] KHAN, N.A., AKHAVAN, B., ZHOU, C., ZHOU, H., CHANG, L., WANG, Y., LIU, Y., BILEK, M.M., LIU, Z. High entropy nitride (HEN) thin films of AICoCrCu0.5FeNi deposited by reactive magnetron sputtering. Surf. Coatings Technol. 2020, vol. 402, 126327.

[13] YAMAMURA Y., TAWARA $\mathrm{H}$. Energy dependence of ion-induced sputtering yields from monatomic solids at normal incidence, Atomic Data and Nuclear Data Tables 1996, vol. 62, pp. 149-253.

[14] EL GARAH, M., ACHACHE, S., MICHAU, A., SCHUSTER F., SANCHETTE, F., Structural and mechanical properties of AITiTaZr $(-\mathrm{N})$ medium entropy films (MEF) obtained by DC magnetron sputtering in dynamic mode, Surf. Coatings Technol. 2020, vol. 396, 125941. 